This is the post-print version of an article published by Springer in European Journal of Applied Physiology. The final publication is available at Springer via http://dx.doi.org/10.1007/s00421-010-1448-0.

Depner CM, RD Kirwan, SJ Frederickson, and MP Miles. Enhanced inflammation with high carbohydrate intake during recovery from eccentric exercise. European Journal of Applied Physiology, 109:1067-1076, 2010.

\title{
Enhanced inflammation with high carbohydrate intake during recovery from eccentric exercise
}

\author{
Mary P. Miles, Chris M. Depner, Rochelle D. Kirwan, Sara J. Frederickson; \\ Department of Health and Human Development, Montana State University, Box 173540, Bozeman, MT 59717, USA
}

\begin{abstract}
Inflammation associated with adipose tissue is modulated by macronutrient availability. For example, glucose increases inflammation in obese but not lean individuals. Little is known about how macronutrient intake influences inflammation associated with muscle. The aim of this study was to determine the impact of macro-nutrient intake differences during recovery from eccentric exercise on the inflammatory response. The study was a cross-over design in which young men and women $(n=12)$ completed high and low carbohydrate $(\mathrm{CHO})$ conditions. Both conditions consisted of six sets of ten maximal high-force eccentric contractions of the elbow flexors and extensors followed by a controlled diet for the first $8 \mathrm{~h}$ post-exercise. Glucose, insulin, tumor necrosis factor- $\alpha$, interleukin (IL)-1 $\beta$, IL-6, and C-reactive protein were measured from blood samples pre-exercise, 1.5, 4, 8, and $24 \mathrm{~h}$ post-exercise. Perceived muscle soreness, strength loss, and serum CK activity were measured through $120 \mathrm{~h}$ post-exercise. Perceived soreness was elevated $(P<0.001)$ at all time points post-exercise in both conditions and was higher $(\mathrm{P}<0.05)$ in the high compared to the low $\mathrm{CHO}$ condition. IL-1 $\beta$ increased $(P=0.05) 24 \mathrm{~h}$ post-exercise in the high compared to the low $\mathrm{CHO}$ condition. There was a trend $(\mathrm{P}=0.06)$ for IL-6 to be elevated in the high compared to the low $\mathrm{CHO}$ condition. We conclude that inflammation induced by high-force eccentric exercise in skeletal muscle is greater when a high $\mathrm{CHO}$ compared to a low $\mathrm{CHO}$ diet is consumed during recovery.
\end{abstract}

\section{Introduction}

Identification of factors influencing inflammation in skel-etal muscle may be helpful in understanding inflammatory muscle diseases and inflammation-based functional impairments that involve skeletal muscle, e.g., insulin resistance (Plomgaard et al. 2005). Prolonged, low-level inflammation is associated with risk of some diseases or related conditions such as metabolic syndrome, type 2 diabetes, and cardiovascular diseases (Grundy et al. 2005; Pearson et al. 2003). Additionally, inflammation influences both injury and adaptation processes in skeletal muscle following exerciseinduced damage (Tidball 2005). The influence of nutritional factors such as the macronutrient composition of the diet on inflammation linked to skeletal muscle is unclear.

Carbohydrate is a macronutrient of particular interest because inflammation linked to obesity and impaired glucose tolerance has been shown to be augmented by hyperglycemia. Glucose intake (75 g) induces oxidative stress and activates pro-inflammatory factors, e.g., tumor necrosis factor- $\alpha$ (TNF- $\alpha$ ) (Dandona et al. 2007). In a study by Gonzalez et al. (2006), acute hyperglycemia in obese, reproductive-aged women caused an increase in TNF- $\alpha$ production. Obese individuals are in a chronic pro-inflammatory state and have elevated levels of inflamma-tory markers. Thus, the inflammatory process was already initiated in the obese test subjects and hyperglycemia further increased this inflammation as seen by an increase in production of the pro-inflammatory cytokine TNF-a.In another study, Esposito et al. (2002) injected three con-secutive boluses of intravenous glucose separated by $2 \mathrm{~h}$ each, inducing acute hyperglycemia with each injection. Acute hyperglycemia induced a significant increase in the pro-inflammatory cytokines TNF-a, interleukin (IL)-6, and IL-18 in both control and impaired glucose tolerance sub-jects. The results of these studies may be an indication that acute hyperglycemia has the ability both to induce an inflammatory response and to increase an inflammatory response that was initiated by another source, such as obesity. However, insulin has anti-inflammatory properties that may offset the influence of glucose ingestion under some circumstances and may differentiate responses 
responses between normal ndividuals and those with impaired glucose tolerance odiabetes (Dandona et al. 2007). It is unclear if rises in blood glucose can enhance acute inflammation in non-obese ndividuals with normal glucose tolerance.

Some types of exercise naturally cause structural dam-age to skeletal muscle resulting in an inflammatory response. Eccentric muscle contractions are defined by the muscle being forcibly lengthened as it contracts (Proske and Morgan 2001). Eccentric muscle exercise in untrained skeletal muscle will cause moderate to high levels of muscle damage resulting in decreased strength, increased soreness, and inflammation (Faulkner et al. 1993). Inflammation is the general response of the body to tissue injury, with the overall goal being healing. The inflam-matory response is a sequential process involving cytokine and chemokine signals, leukocytes, oxidative stress, and acute phase proteins. All elements of this process have been measured following high-force eccentric exercise (Smith and Miles 2000). The general cytokine cascade in sequential order is TNF- $\alpha$, IL-1 $\beta$, IL-6, IL-1ra, and IL-10 (Petersen and Pedersen 2005). TNF- $\alpha$ and IL-1 $\beta$ induce lymphocytes, neutrophils, monocytes, and other cells to clear antigens and heal tissue (Ostrowski et al. 1999). TNF$\alpha$ and IL- $1 \beta$ also induce the production and release of IL-6. IL-6 promotes some of the proteins in the acute phase response (systemic response), most notably C-reactive protein (CRP).

Exercise recovery nutrition is aimed at consuming some protein and enough carbohydrate $(\mathrm{CHO})$ to generate a rise in insulin that will enhance muscle glycogen replenish-ment, protein synthesis, and recovery adaptations (Manninen 2006; Ivy et al. 2008). Previously, we had subjects consume an additional $0.25 \mathrm{~g}$ of carbohydrate per kilogram body weight per hour for $12 \mathrm{~h}$ on top of a baseline diet of $50 \%$ carbohydrate on both the day of and the day following exercise. This did not affect IL-6, CRP, or cortisol responses following eccentric exercise (Miles et al. 2007). This was a relatively low CHO load spread out over the course of $48 \mathrm{~h}$. More research is needed to determine whether greater consumption of high $\mathrm{CHO}$ foods earlier in recovery from exercise, when high CHO intake is encouraged for recovery, influences the inflammation process.

The purpose of this study was to determine if macro-nutrient intake differences following eccentric exercise influence the inflammation response. We utilized high-force eccentric muscle contractions to induce an acute inflammatory response. The subjects were fed either a high $\mathrm{CHO}$ or low $\mathrm{CHO}$ diet for the first several hours post-exercise. We hypothesized that the inflammatory response (TNF- $\alpha$, IL-1 $\beta$, IL-6, and CRP) would be higher in the high CHO compared to the low $\mathrm{CHO}$ condition. An improved understanding of inflammation in skeletal muscle will help define the role skeletal muscle has in inflammation asso-ciated with metabolic diseases, particularly those linked to insulin resistance (Tilg and Moschen 2008).

\section{Methods \\ Subjects}

Fourteen subjects enrolled in the investigation and two did not complete the study due to illness not related to this study. The remaining 12 subjects were 19-36 years of age (male 7, female 5). Both male and female subjects were included in this study. In an effort to reduce the influence of differences in sex, each subject acted as his or her own control. Further, we tested for sex differences in a previous study using a similar exercise ( 29 men, 22 women) and found that inflammation responses to this exercise were similar between the sexes (Miles et al. 2008). Without including both male and female the $N$ would have been reduced and not large enough for significance in many cases. Subjects were non-weight trained and did not do any heavy lifting or lowering with the arms that resulted in soreness of the arms in the 6 months prior to the study. The goal of these criteria was to eliminate the possible effects of the repeated bout effect. This occurs when muscle exposed to eccentric contractions produces a protective adaptation that results in decreased muscle damage with subsequent bouts of eccentric exercise for up to several months (Nosaka et al. 1991). Individuals were excluded if they had a known history or condition of anemia, muscu-loskeletal limitations, inflammatory conditions, diabetes mellitus, heart disease, known kidney problems (excluding kidney stones), smoking, alcohol use greater than 1 drink per day for women and 2 drinks per day for men, binge drinking (greater than 4 drinks on any one occasion), chronic use of anti-inflammatory medications, use of lipid lowering medications, use of oral contraceptives, regular physical activity that results in bruising or muscle soreness, and pregnancy. To aid in determining exclusion criteria all potential subjects were required to fill out a Health History Questionnaire, a Physical Activity Readiness Question-naire, and via interview by an investigator, asked several questions regarding the use of their arms during work and recreational activities to determine whether they were likely to have performed heavy lifting or lowering with their arms. Additionally, all subjects were instructed to refrain from using any anti-inflammatory medications throughout the duration of the study. All subjects were informed of the risks and discomforts associated with participation and were required to sign an informed consent document approved by the Montana State University Human Subjects Committee prior to participation. 


\section{Research design}

The research design was a cross-over protocol in which each subject acted as his or her own control. Each subject completed a high $\mathrm{CHO}$ and a low $\mathrm{CHO}$ condition. The order of conditions was counterbalanced between subjects and separated by 3-6 weeks within each subject to allow variables to return to baseline between conditions. We have previously used a similar washout period with a similar exercise protocol and observed no differences between conditions for baseline values, suggesting this is a suffi-cient amount of time for a washout period (Miles et al. 2007). Also, women began each condition within 4 days of the onset of menstrual bleeding to minimize the effect of cyclical hormone variation. On the first morning of each condition, subjects performed high-force eccentric exercise to induce muscle soreness and inflammation. Then, sub-jects were provided either a high $\mathrm{CHO}$ or low $\mathrm{CHO}$ diet for the first $8 \mathrm{~h}$ post-exercise. Each diet consisted of three meals at $0.5,3$, and $7 \mathrm{~h}$ post-exercise. The high CHO diet consisted of corn flakes, $2 \%$ milk, apple juice, and Clif $\operatorname{bar}(\mathrm{s})^{\mathrm{TM}}$. The macronutrient composition of this diet was $75 \%$ carbohydrate, $15 \%$ fat, and $10 \%$ protein with each subject ingesting $1.45 \mathrm{~g}$ carbohydrate per kilogram body weight. The low CHO diet consisted of turkey, cheese, and peanuts. The macronutrient composition of this diet was $6 \%$ carbohydrate, $70 \%$ fat, and $24 \%$ protein with each subject ingesting $0.11 \mathrm{~g}$ carbohydrate per kilogram body weight. The diets contained equivalent kilocalories pro-portional to weight within each subject between conditions. The main goal when designing the diets was to keep them isocaloric, easy to prepare, all while adjusting the $\mathrm{CHO}$ load. However, the consequence of this resulted in different fat and protein compositions between the diets as well. This is a limitation of the current study, and any measured changes in inflammation cannot be solely attributed to differing $\mathrm{CHO}$ intake. While the subjects could clearly identify differences in the diets, the expected outcomes and influences of the diets were not discussed with the subjects in an effort to not bias the results.

The baseline assessment and blood draw occurred at 7:00 a.m. prior to exercising on the first day of each con-dition for all subjects for both conditions. Post-exercise strength and soreness assessments were made immediately post-exercise, $1.5,4,8,24,48,72,96$, and $120 \mathrm{~h}$ post-exercise. Blood samples were collected pre-exercise, $1.5,4,8$, and $24 \mathrm{~h}$ postexercise for assessment of inflammation. An additional blood sample was collected $120 \mathrm{~h}$ post-exercise for analysis of serum CK activity and CRP.

To minimize variability, subjects were required to adhere to several restrictions prior to and during the time of assessment. To obtain optimal baseline assessment of blood, subjects were required to be on an overnight fast and keep physical activity to a minimum the first morning of each condition. Food intake was not controlled or monitored prior to the overnight fast. It was beyond the resources of the study to do so and thus is a limitation of the study as this prior food intake could possibly impact the resulting inflammatory response from the exercise. On subsequent morning blood draws within each condition subjects were required to be fasted at least $8 \mathrm{~h}$ and keep physical activity to a minimum. The day prior to and during the assessment period, subjects were required to refrain from strenuous physical activity and physical activity that lasted longer than $60 \mathrm{~min}$ in duration. Additionally, from the time of recruitment through com-pletion of the study subjects were instructed not to perform any physical activity they were unaccustomed to or did not do on a regular basis prior to participating in the study. To reduce the influence of illness on inflammatory factors, subjects were only tested if they had been free from known infection for at least 1 week prior to testing.

\section{Anthropometric measurements}

Prior to any testing each subject was assessed for anthro-pometric measurements. Anthropometric measurements consisted of body height and weight, and waist to hip ratio. For the waist to hip ratio a circumference measure was taken at the waist (narrowest point between the ribs and the hips at the end of a normal expiration) and hip (at the level of the greater trochanter) using an anthropometric tape measure. This measure was made over the clothing of the subject (no disrobing occurred).

\section{Eccentric exercise and maximal force production}

A computer-controlled isokinetic dynamometer (Kin Com 125E+, Chattecx Corporation, Chattanooga, TN) was used to perform the high force eccentric exercise. The elbow flexor and extensor muscles of one arm were exercised for each condition. For example, if a subject exercised his or her left arm for the high $\mathrm{CHO}$ condition then he or she exercised the right arm for the low $\mathrm{CHO}$ condition. The exercise protocol was similar to previous exercise proto-cols used in our lab to allow some comparison between the current study and previous studies (Miles et al. 2007, 2008). The point of rotation in the dynamometer was aligned with the axis of rotation in the elbow. The dyna-mometer was connected to the arm just below the wrist via a padded support and Velcro strap. Subjects started with their elbow in a fully flexed position. The 
dynamometer then moved the elbow to a fully extended position. The subjects were instructed to maximally resist the movement of the elbow being extended by attempting to keep the elbow in a fully flexed position. From the fully extended position, the dynamometer then moved the elbow to a fully flexed position. Subjects also maximally resisted this movement. The movement of the elbow from flexed to extended position and back to flexed position consisted of one repetition. The angular velocity of the dynamometer was set at 0.79 radians $\left(45^{\circ}\right)$ per second. There was a 10 -s pause in between each repetition. There were ten repeti-tions per set with a total of six sets. There was a 5-min rest period between sets. Just prior to the exercise, subjects were given a warm-up and familiarization period to acquaint themselves with the movement of the dynamom-eter and to ensure their muscles were prepared for maximal force contractions. As the exercise was mechanically very simple, we believe this familiarization period just prior to exercising was sufficient to eliminate any potential differences between the bouts of exercise due to familiarity with the dynamometer and the exercise itself.

Maximal isometric strength was measured pre-exercise, immediately post-exercise, 24, 48, 72, 96, and $120 \mathrm{~h}$ postexercise. The dynamometer was adjusted for each subject the same way as it was adjusted during the high-force eccentric exercise. To test maximal isometric strength the dynamometer was set so the elbow was at an angle of $1.57 \mathrm{rad} .\left(90^{\circ}\right)$. The dynamometer was locked in that position and the subject was instructed to flex or extend their elbow with maximal effort for $3 \mathrm{~s}$. For each measure of maximal isometric strength, the subject performed this procedure three times, and the average of the three trials was used as the maximal isometric strength for that specific time. There was a 30-s rest period in between the three trials for each measure of maximal isometric strength.

\section{Muscle soreness}

Perceived muscle soreness was evaluated with the aid of a visual analog scale at pre-exercise, 1.5, 4, 8, 24, 48, 72,96 , and $120 \mathrm{~h}$ post-exercise. The scale consisted of a $100-\mathrm{mm}$ line with one end representing no soreness and the other end representing extreme soreness. The subjects were asked to flex and extend their arms several times while holding a 1-kg weight in their hand and putting pressure on both their flexor and extensor muscles with their other hand. Then the subjects placed a vertical line on the scale representing their perceived level of soreness. The subjects were instructed to place a line on the scale in terms of soreness only, not in comparison to other types of pain, e.g., not relative to a broken bone.

\section{Blood analysis}

Blood was collected using a standard venipuncture tech-nique at pre-exercise, 1.5, 4, 8, 24, and $120 \mathrm{~h}$ post-exercise. Blood was collected from an antecubital vein into chilled evacuated tubes without additive for analysis of glucose, CRP and $\mathrm{CK}$, and containing EDTA for TNF- $\alpha$, IL-6, IL- $1 \beta$, and insulin. The tube without additive was allowed to clot at room temperature and the tube with EDTA was kept chilled on ice until centrifugation within $30 \mathrm{~min}$. Serum and plasma were separated from cells using a refrigerated 21000R Marathon centrifuge (Fisher Scientific, Pittsburgh, PA). Samples were stored at $-80^{\circ} \mathrm{C}$ until analysis.

Serum high-sensitivity CRP (MP Biomedicals, Irvine, CA), plasma high-sensitivity TNF- $\alpha$ (R\&D Systems, Minneapolis, MN), plasma high-sensitivity IL-6 (R\&D Sys-tems, Minneapolis, MN), plasma high-sensitivity IL-1 $\beta$ (R\&D Systems, Minneapolis, MN), and insulin (Diagnostic Systems Laboratories, Inc., Webster, TX) concentrations were measured using commercially available ELISA kits according to the instructions of the manufacturers. Absor-bance of 96well plates was read at the primary wavelength and corrected for secondary wavelength interference using a $\mu$ Quant Universal microplate spectrophotometer (Bio-Tek Instruments, Winooski, VT). All samples were run in duplicate. All samples for a given subject were run on the same assay plate. Average intra-assay coefficients of var-iation (CV) between duplicate samples were 13.8, 16.2, 9.7, 8.2, and 5.0\% for CRP, TNF- $\alpha$, IL-6, IL-1 $\beta$, and insulin, respectively. These are within a twofold range of the intra-assay $\mathrm{CV}$ values determined by the manufacturers for 20 or more samples at comparable concentrations.

Serum CK activity was measured using an ultraviolet, kinetic assay utilizing a creatine kinase $n$-acetyl-L-cysteine reagent at $37^{\circ} \mathrm{C}$ in which $\mathrm{CK}$ activity is proportional to the change in NADH production and the increase in absorbance at $340 \mathrm{~nm}$ (CK-NAC reagent, Thermo Fisher Scientific, Inc., Waltham, MA). Serum glucose concentration was assayed using a glucose hexokinase reagent set in which glucose is converted to glucose-6-phosphate and then to 6-phosphogluconate with the reduction of NAD+ to NADH (Pointe Scientific, Inc. Canton, MI). The absorbance of NADH at $340 \mathrm{~nm}$ is directly proportional to the concentration of glucose in the sample and calculated rela-tive to a known standard. These assays were modified for microplate analysis and read using a lQuant Universal microplate spectrophotometer (Bio-Tek Instruments, Winooski, VT). Samples were run in duplicate. All samples for a given subject were analyzed in the same run of the assay. Intra-assay coefficients of variation were 3.1 and $7.8 \%$ for CK and glucose, respectively. 


\section{Statistics}

Data were analyzed using Statistical Program for Social Sciences (SPSS) for Windows (version 13.0, SPSS Inc., Chicago, IL). Baseline measurements between conditions were analyzed using a paired samples $t$ test for continuous variables. To compare conditions over time, a two-way repeated measures analysis of variance (ANOVA) was used. All variables were normally distributed, as determined using the Kolmogorov-Smirnov test. If there were significant main effects or interactions found, paired $t$ tests analyses were run to determine the location of the significant differences. Statistical significance was set at an alpha level of 0.05 .

\section{Results}

Subject characteristics

Six subjects completed the high $\mathrm{CHO}$ condition first and six subjects completed the low $\mathrm{CHO}$ condition first. Subjects were aged $24.8 \pm 6.0$ years and weighing $72.9 \pm 9.7 \mathrm{~kg}$. Subjects' mean BMI and waist:hip ratio were $23.8 \pm 2.9 \mathrm{k} \mathrm{g} \mathrm{m}^{-2}$ and $0.86 \pm 0.08$, respectively. Baseline concentrations of TNF- $\alpha$, IL-1 $\beta$, IL-6, CRP, glucose, and insulin for both conditions are presented in Table 1. Very small, but statistically different baseline concentrations were measured for insulin, where the high $\mathrm{CHO}$ condition was slightly greater, and for TNF- $\alpha$, where the low $\mathrm{CHO}$ condition was slightly greater.

\section{Blood glucose and insulin}

Blood glucose concentrations were similar between con-ditions, with no significant changes over time. Insulin concentrations were significantly higher $(P<0.001)$ in the high $\mathrm{CHO}$ condition compared to the low $\mathrm{CHO}$ condition at all time points except $24 \mathrm{~h}$ post-exercise (Fig. 1). Additionally, all post-exercise time points in the high $\mathrm{CHO}$ condition were greater than the pre-exercise time point.

Table 1 Baseline values of TNF- $\alpha$, IL-6, IL-1, CRP, CK, glucose, and insulin for high and low $\mathrm{CHO}$ conditions

\begin{tabular}{|c|c|c|c|}
\hline Parameters & Mean & SD & $P$ value \\
\hline \multicolumn{4}{|l|}{$\mathrm{TNF}-\alpha\left(\mathrm{pg} \mathrm{ml}^{-1}\right)$} \\
\hline High carbohydrate & 1.86 & 0.97 & \multirow[t]{2}{*}{0.031} \\
\hline Low carbohydrate & 2.24 & 1.32 & \\
\hline \multicolumn{4}{|l|}{ IL-6 $\left(\mathrm{pg} \mathrm{ml}^{-1}\right)$} \\
\hline High carbohydrate & 1.89 & 1.44 & \multirow[t]{2}{*}{0.213} \\
\hline Low carbohydrate & 1.43 & 0.98 & \\
\hline \multicolumn{4}{|l|}{ IL-1 $\beta\left(\mathrm{pg} \mathrm{ml}^{-1}\right)$} \\
\hline High carbohydrate & 0.19 & 0.14 & \multirow[t]{2}{*}{0.464} \\
\hline Low carbohydrate & 0.21 & 0.18 & \\
\hline \multicolumn{4}{|l|}{$\mathrm{CRP}\left(\mathrm{mg}^{-1}\right)$} \\
\hline High carbohydrate & 1.81 & 3.14 & \multirow[t]{2}{*}{0.853} \\
\hline Low carbohydrate & 1.60 & 2.75 & \\
\hline \multicolumn{4}{|l|}{$\mathrm{CK}\left(\mathrm{IU} 1^{-1}\right)$} \\
\hline High carbohydrate & 279.60 & 241.23 & \multirow[t]{2}{*}{0.213} \\
\hline Low carbohydrate & 191.36 & 103.33 & \\
\hline \multicolumn{4}{|l|}{ Glucose (mmol) } \\
\hline High varbohydrate & 5.82 & 0.50 & \multirow[t]{2}{*}{0.286} \\
\hline Low carbohydrate & 5.55 & 0.77 & \\
\hline \multicolumn{4}{|l|}{ Insulin $\left(\mu \mathrm{IU} \mathrm{ml} \mathrm{m}^{-1}\right)$} \\
\hline High carbohydrate & 19.68 & 8.27 & \multirow[t]{2}{*}{0.015} \\
\hline Low carbohydrate & 16.03 & 7.38 & \\
\hline
\end{tabular}

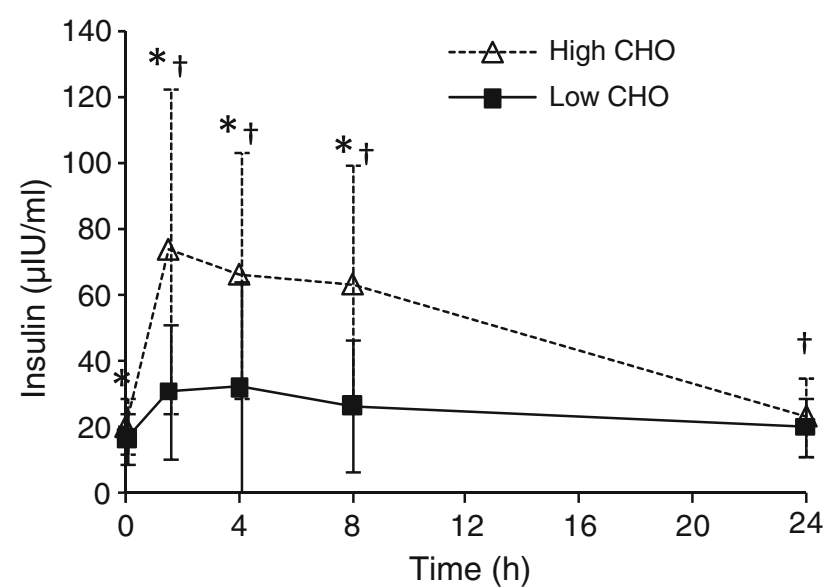

Fig. 1 Insulin concentrations in high and low $\mathrm{CHO}$ conditions at preexercise, $1.5,4,8$, and $24 \mathrm{~h}$ post-exercise. Values are mean $\pm \mathrm{SD}$, CHO carbohydrate, $n=10$. $* P<0.001$ compared to the low $\mathrm{CHO}$ condition; ${ }^{\dagger} P<0.05$ compared to pre-exercise

$p g$ picograms, $m g$ milligrams, $k g$ kilograms, $m$ meter, $m l$ milliliter, $d l$ deciliter, $L$ liter, $I U$ international units, $\mu I U$ micro-international units

\section{Markers of muscle damage}

Perceived muscle soreness was elevated $(\mathrm{P} \backslash 0.001)$ at all time points post-exercise in both conditions and there was a main condition effect $(P<0.05)$ with higher ratings of perceived soreness in the high $\mathrm{CHO}$ condition. Post-exercise isometric strength loss in the biceps was similar between conditions with significant strength loss $(P<0.001)$ immediately post-exercise, 24, and $48 \mathrm{~h}$ post-exercise in both conditions. Post-exercise strength loss in 
Table 2 Perceived muscle soreness, percent strength loss, and CK values at all time points measured for both conditions

\begin{tabular}{|c|c|c|c|c|c|c|c|c|}
\hline \multirow[t]{2}{*}{ Time (h) } & \multicolumn{2}{|l|}{ Soreness } & \multicolumn{2}{|c|}{$\%$ Strength loss biceps } & \multicolumn{2}{|c|}{$\%$ Strength loss triceps } & \multicolumn{2}{|l|}{ CK } \\
\hline & High $\mathrm{CHO}^{\mathrm{b}}$ & Low $\mathrm{CHO}$ & High CHO & Low CHO & High CHO & Low $\mathrm{CHO}$ & High $\mathrm{CHO}$ & Low $\mathrm{CHO}$ \\
\hline Pre & $3.2 \pm 4.7$ & $0.64 \pm 1.0$ & 0 & 0 & 0 & 0 & $279.6 \pm 241.2$ & $191.4 \pm 103.3$ \\
\hline Post & N/A & N/A & $-12.0 \pm 13.2^{\mathrm{a}}$ & $-16.3 \pm 11.2^{\mathrm{a}}$ & $-3.7 \pm 21.8$ & $-11.0 \pm 25.1$ & N/A & N/A \\
\hline 1.5 & $17.6 \pm 15.0^{\mathrm{a}}$ & $11.7 \pm 12.1^{\mathrm{a}}$ & N/A & N/A & N/A & N/A & N/A & N/A \\
\hline 4 & $16.8 \pm 16.6^{\mathrm{a}}$ & $7.3 \pm 6.5^{\mathrm{a}}$ & N/A & N/A & N/A & N/A & N/A & N/A \\
\hline 8 & $21.7 \pm 17.2^{\mathrm{a}}$ & $9.9 \pm 6.5^{\mathrm{a}}$ & N/A & N/A & N/A & N/A & N/A & N/A \\
\hline 24 & $48.1 \pm 23.6^{\mathrm{a}}$ & $35.2 \pm 25.3^{\mathrm{a}}$ & $-19.8 \pm 18.3^{\mathrm{a}}$ & $-7.0 \pm 20.5^{\mathrm{a}}$ & $-11.8 \pm 27.5$ & $-1.0 \pm 29.1$ & $241.6 \pm 158.0$ & $188.6 \pm 141.4$ \\
\hline 48 & $50.1 \pm 29.6^{\mathrm{a}}$ & $46.8 \pm 24.9^{\mathrm{a}}$ & $-12.5 \pm 15.8^{\mathrm{a}}$ & $-7.1 \pm 19.4^{\mathrm{a}}$ & $-0.5 \pm 30.6$ & $2.2 \pm 32.8$ & N/A & N/A \\
\hline 72 & $30.1 \pm 21.5^{\mathrm{a}}$ & $34.7 \pm 17.6^{\mathrm{a}}$ & $-2.4 \pm 12.2$ & $-1.0 \pm 18.8$ & $4.8 \pm 32.8$ & $8.5 \pm 35.1$ & N/A & N/A \\
\hline 96 & $16.9 \pm 13.5^{\mathrm{a}}$ & $11.2 \pm 5.8^{\mathrm{a}}$ & $3.5 \pm 10.2$ & $2.6 \pm 16.5$ & $12.4 \pm 24.3$ & $12.6 \pm 37.4$ & N/A & N/A \\
\hline 120 & $7.6 \pm 7.0^{\mathrm{a}}$ & $2.8 \pm 2.8^{\mathrm{a}}$ & $0.0 \pm 17.3$ & $3.5 \pm 19.0$ & $15.7 \pm 22.4$ & $8.1 \pm 23.1$ & $242.7 \pm 204.7$ & $179.3 \pm 120.3$ \\
\hline
\end{tabular}

Perceived muscle soreness was evaluated on a $100 \mathrm{~mm}$ visual analog scale. Strength loss was measured as percent strength loss compared to baseline measurements made pre-exercise. $\mathrm{CK}$ is given as IU/L. Data are mean $\pm \mathrm{SD}$

${ }^{\text {a }} P<0.001$ compared to baseline

${ }^{\text {b } P}<0.05$ compared to low $\mathrm{CHO}$ condition (condition effect)

the triceps was similar between conditions with no decreases in strength at any time points post-exercise. CK was parallel between conditions with no significant chan-ges post-exercise. Data for perceived muscle soreness, percent strength loss, and $\mathrm{CK}$ are presented in Table 2.

\section{Markers of inflammation}

TNF- $\alpha$ was similar between conditions with no significant changes post-exercise (Fig. 2). IL-1 $\beta$ was higher $(P=0.05)$ in the high $\mathrm{CHO}$ condition compared to the low $\mathrm{CHO}$ condition $24 \mathrm{~h}$ post-exercise (Fig. 3). There was a trend $(P=0.06)$ for a main condition effect for IL-6 concentrations to be higher in the high $\mathrm{CHO}$ condition. IL- 6 decreased $(P<0.05)$ at 1.5 and 4 h postexercise, and there was a trend $(P=0.09)$ for an increase $8 \mathrm{~h}$ post-exercise in both conditions (Fig. 4). CRP was similar between conditions with no significant changes post-exer-cise (Fig. 5).

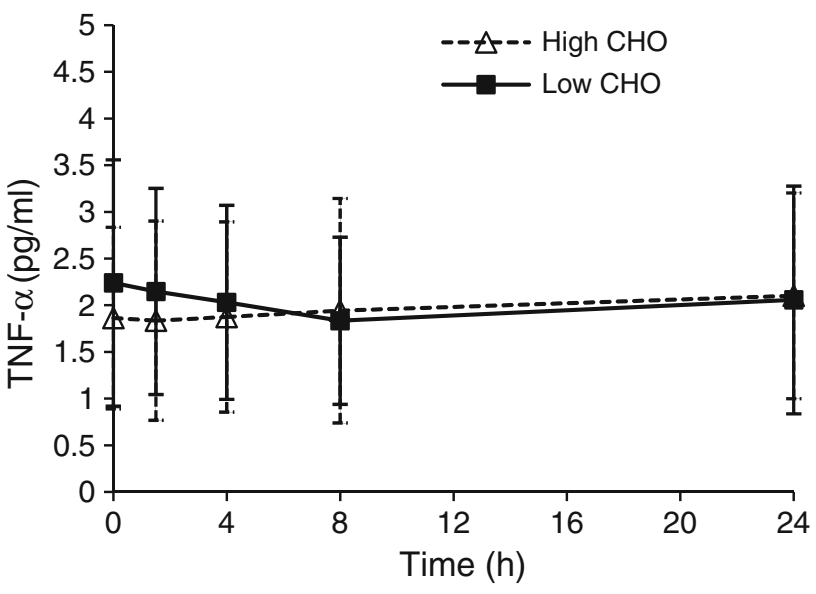

Fig. 2 TNF- $\alpha$ concentrations in high and low CHO conditions at preexercise, $1.5,4,8$, and $24 \mathrm{~h}$ post-exercise. Values are mean $\pm \mathrm{SD}$, $\mathrm{CHO}$ carbohydrate

\section{Discussion}

The purpose of this investigation was to determine the influence of macronutrient intake differences following eccentric exercise on the inflammation response. The main finding of the study was that the responses of IL- $1 \beta$ and soreness were greater in the high compared to the low $\mathrm{CHO}$ condition during recovery from eccentric resistance exer-cise. In an earlier investigation of the influence of carbo-hydrate supplementation during recovery from eccentric exercise on the inflammatory process, Miles et al. (2007) found that adding $0.25 \mathrm{~g} \mathrm{~kg}^{-1} \mathrm{~h}^{-1} \mathrm{CHO}$ to a background diet of $50 \% \mathrm{CHO}$ during recovery from muscle soreness-inducing exercise did not affect the muscle damage or IL-6 response that occurs several hours post-exercise. In the current study, CHO intake of $4.35 \mathrm{~g} \mathrm{~kg}-1$ in the high $\mathrm{CHO}$ condition across three meals during the first $8 \mathrm{~h}$ post-exercise induced a delayed IL-1b response 24 -h post-exercise and greater muscle soreness relative to an isoca-loric low $\mathrm{CHO}$ condition. While there was a trend for IL-6 to be higher in the high CHO condition, this was not sig-nificant and is similar to our finding in our previous study. The subjects in this study had good glycemic control, as evidenced by the lack of increase in blood glucose $1 \mathrm{~h}$ after each of the three high CHO meals. In individuals with healthy insulin responses and insulin sensitivity, high $\mathrm{CHO}$ foods cause a sharp increase in blood glucose followed by a 


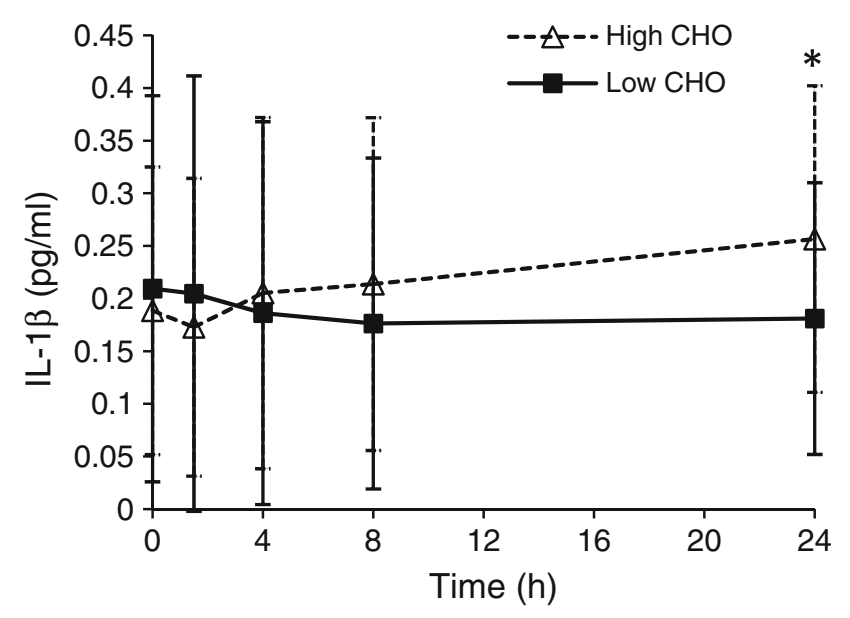

Fig. 3 IL- $1 \beta$ concentrations in high and low $\mathrm{CHO}$ conditions at preexercise, $1.5,4,8$, and $24 \mathrm{~h}$ post-exercise. Values are mean $\pm \mathrm{SD}$, $\mathrm{CHO}$ carbohydrate. ${ }^{*} \mathrm{P}=0.05$ compared to the low $\mathrm{CHO}$ condition at $24 \mathrm{~h}$ post-exercise

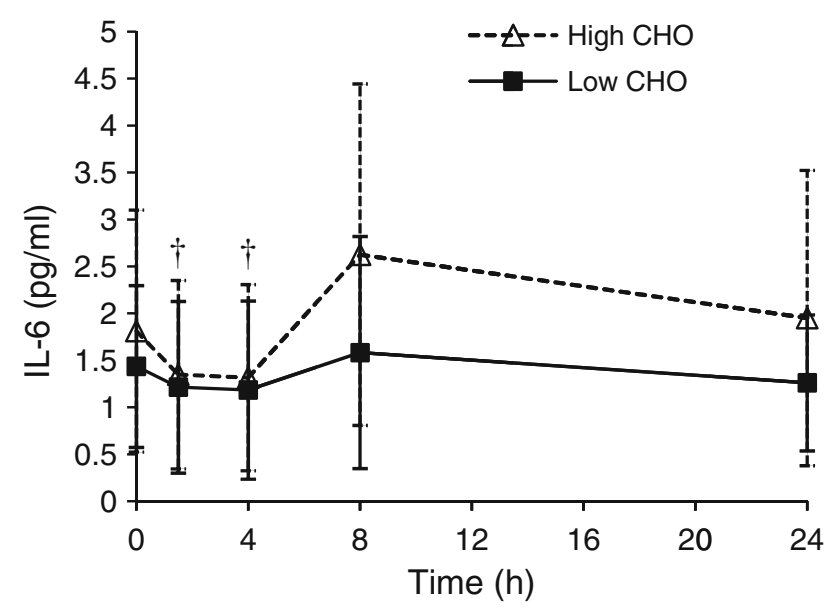

Fig. 4 IL-6 concentrations in high and low $\mathrm{CHO}$ conditions at preexercise, $1.5,4,8$, and $24 \mathrm{~h}$ post-exercise. There was a time effect where IL- 6 was decreased at 1.5 and $4 \mathrm{~h}$ post-exercise and a trend for IL-6 to be increased $8 \mathrm{~h}$ post-exercise. Values are mean $\pm \mathrm{SD}$, $\mathrm{CHO}$ carbohydrate. ${ }^{\dagger} \mathrm{P}<0.05$ compared to pre-exercise

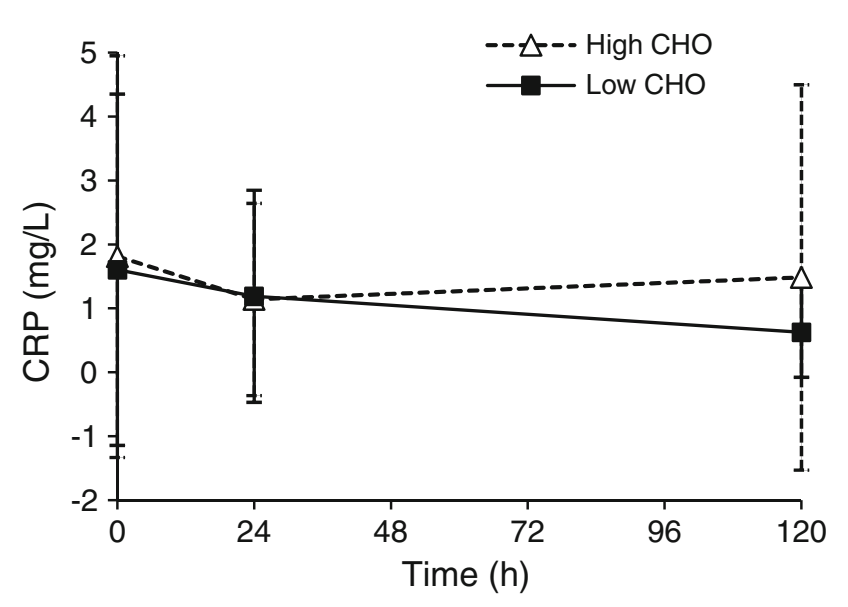

Fig. $5 \mathrm{CRP}$ concentrations in high and low $\mathrm{CHO}$ conditions at pre-exercise, 24 and $120 \mathrm{~h}$ post-exercise. Values are mean $\pm \mathrm{SD}$, $\mathrm{CHO}$ carbohydrate

the skeletal muscle from elevated IL- $1 \beta$ could result in increased perceived muscle soreness. Secondly, IL- $1 \beta$ has been shown to enhance production of prostaglandin E2 $\left(\mathrm{PGE}_{2}\right)$ in skeletal muscle (Moldawer et al. 1987). Elevated levels of $\mathrm{PGE}_{2}$ and muscle soreness after eccentric exercise have been found to coincide suggesting a relationship between IL-1 $\beta, \mathrm{PGE}_{2}$, and muscle soreness (Pedersen et al. 1998). The elevated IL-1 $\beta 24 \mathrm{~h}$ post-exercise in the high $\mathrm{CHO}$ condition could have augmented $\mathrm{PGE}_{2}$ synthesis in the skeletal muscle, increased sensitivity to pain, and led to increased perceived muscle soreness post-exercise. Thus, higher IL- $1 \beta$ and soreness may reflect enhanced inflammation in the high $\mathrm{CHO}$ compared to low $\mathrm{CHO}$ condition. Additionally, we infer from these findings that the inflammation-stimulating effects of the high $\mathrm{CHO}$ condition outweighed the potential anti-inflammatory effects of insulin, as reported in previous research (Dandona et al.2007).

A comparison of the IL-1b increase in the present study to the findings of other investigations provides further evi-dence that $\mathrm{CHO}$ intake has the ability to

sharp decline back to baseline (Foster-Powell et al. 2002). The 1.5, 4, and $8 \mathrm{~h}$ post-exercise blood draws were taken $1 \mathrm{~h}$ after each meal was consumed. The significant rise in insulin in the high $\mathrm{CHO}$ compared to low $\mathrm{CHO}$ condition supports the fact that the subjects received a much greater load of $\mathrm{CHO}$ during this condition.

Consistent with our hypothesis that high CHO intake would increase inflammation, IL-1 $\beta$ was higher in the high $\mathrm{CHO}$ condition compared to the low $\mathrm{CHO}$ condition at $24 \mathrm{~h}$ post-exercise. Further, the elevation in IL- $1 \beta$ is consistent with increased soreness in the high $\mathrm{CHO}$ condition via two possible mechanisms. First, IL-1 $\beta$ has been shown to enhance skeletal muscle protein breakdown (Flores et al. 1989; Nawabi et al. 1990). Elevated protein breakdown in augment the inflammatory cytokine response. Several other studies have used models of eccentric exercise and found no significant changes in IL-1b $24 \mathrm{~h}$ post-exercise (Bruunsgaard et al. 1997; Smith et al. 2000; Hirose et al. 2004). Smith et al.(2000) actually observed significant decreases in IL-1b $24 \mathrm{~h}$ post-exercise. An increase in the pro-inflammatory cyto-kines TNF-a and IL-1b is expected at the onset of inflam-mation. The general cytokine cascade in sequential order is TNF-a, IL-1b, IL-6, IL-1ra, and IL-10 (Petersen and Pedersen 2005). While the increase in IL-1b may have been expected earlier than $24 \mathrm{~h}$ post-exercise, recent research by Davis et al. (2007) measured increases in TNF-a, IL-1b, and IL-6 in rat soleus muscle 24-48 h following eccentrically biased downhill running, and Silva et al. (2008) measured increases in TNF-a in plasma $48 \mathrm{~h}$ following 
eccentric exercise similar to that in the present investigation. Furthermore, Loram et al. (2007) demonstrated that IL-1 $\beta$ release from skeletal muscle during inflammation is delayed up to $24 \mathrm{~h}$ and thus supports the timing of our finding of elevated IL-1 $\beta 24 \mathrm{~h}$ post-exercise. Thus, the timing of the increase in IL-1 $\beta$ is appropriate to the exercise stimulus, and increased IL- $1 \beta$ in the high $\mathrm{CHO}$ but not low $\mathrm{CHO}$ condi-tion $24 \mathrm{~h}$ post-exercise supports the idea that carbohydrates enhanced the inflammatory response.

The IL-6 response we measured is consistent with either no effect or a small enhancement of inflammation with high $\mathrm{CHO}$ intake following eccentric exercise. There was a trend $(P=0.06)$ for IL-6 to be higher in the high CHO condition compared to the low $\mathrm{CHO}$ condition with the greatest difference $8 \mathrm{~h}$ post-exercise. IL- 6 follows a diurnal pattern of being higher at 7:00 a.m. compared to 12:00 or 4:00 p.m. (Miles et al. 2008). As such, there was a trend for an increase at a time when there would typically be a decrease. With respect to our previous work with a lower CHO dose (Miles et al. 2007), a greater influence of $\mathrm{CHO}$ toward increasing the IL-6 response was measured in the present study.

An anti-inflammatory effect of the low CHO diet was not likely to have occurred because the IL-6 levels in the low $\mathrm{CHO}$ condition in this study were comparable to what was observed in the placebo condition in our previous work (Miles et al. 2007). Even so, with the current study design it cannot be ruled out that the low CHO condition did not attenuate the inflammation and muscle damage to some degree. It has previously been shown that protein, and spe-cifically the branched chain amino acids have the ability to decrease muscle damage and promote repair when ingested post-exercise, and therefore attenuate the resulting inflam-mation (Negro et al. 2008). The low CHO condition con-tained $24 \%$ of kcals as protein whereas the high $\mathrm{CHO}$ condition only had $10 \% \mathrm{kcals}$ as protein. Thus, this greater protein intake in the low $\mathrm{CHO}$ condition could have con-tributed to the lower inflammation and soreness observed in this condition and is a limitation of the current investigation. It is beyond the scope of this study to determine the exact influence of the differences in protein between conditions. Further research investigating the role of post-exercise pro-tein in combination with CHOs and inflammation is needed.

Normally, endurance exercise causes a significant increase in circulating IL-6 (Petersen and Pedersen 2005). It is accepted that the elevated IL-6 resulting from endur-ance exercise is released directly from skeletal muscle and promotes liver glycogen breakdown and lipolysis of fatty acids in adipose tissue (Petersen and Pedersen 2005). This response elevates blood glucose and provides additional fuel for the skeletal muscle. It has previously been dem-onstrated that $\mathrm{CHO}$ intake of $0.96 \mathrm{~g} \mathrm{~kg}^{-1} \mathrm{~h}^{-1}$ and lower decreases this IL-6 response associated with endurance exercise (Nehlsen-Cannarella et al. 1997; Nieman et al. 2004; Miles et al. 2006). It is believed the external CHO intake provides sufficient fuel for the skeletal muscles and there is less of an energy requirement on the liver and adipose tissue and thus less IL-6 secreted from skeletal muscle. In the current study, the dose of $1.45 \mathrm{~g} \mathrm{~kg}-1$ in three post-exercise boluses did not decrease the IL-6 response. This is in agreement with our hypothesis that the observed changes in IL-6 are resulting from an inflamma-tory response and not due to changes in glucose metabo-lism as with endurance exercise. Thus, we conclude that the influence of CHO intake on IL-6 differs depending on the type of exercise and when the $\mathrm{CHO}$ is consumed. It is clear that endurance exercise induces a large IL-6 response that is attenuated by $\mathrm{CHO}$ intake before and during exer-cise, whereas eccentric exercise induces a smaller IL-6 response that is somewhat augmented by $\mathrm{CHO}$ intake consumed during the early recovery period.

We did not measure changes in TNF- $\alpha$ in response to the exercise in either of the conditions. Up-regulation of the pro-inflammatory transcription factor NF-kB, increases in TNF- $\alpha$ gene expression by monocytes, and increases in TNF- $\alpha$ plasma concentrations in obese but not lean indi-viduals after glucose ingestion have been measured in previous studies (Beutler et al. 1985; Gonzalez et al. 2006). However, many studies fail to measure acute increases in plasma TNF- $\alpha$ from healthy individuals in response to glucose intake or eccentric exercise (Hirose et al. 2004; Gonzalez et al. 2006). Alternatively, given the measure-ment of increased plasma TNF- $\alpha 48 \mathrm{~h}$ post-exercise by (Silva et al. 2008), it is possible that changes in TNF- $\alpha$ occurred after our $24 \mathrm{~h}$ post-exercise measurement. Addi-tionally, TNF- $\alpha$ has a half life in the plasma of 6 min unless bound by a soluble receptor (Beutler et al. 1985; Aderka et al. 1998). Thus, while we did not measure enhanced TNF- $\alpha$ plasma concentrations in the high $\mathrm{CHO}$ compared to low $\mathrm{CHO}$ condition, it is possible that potential differences were not captured in plasma concen-trations at the times measured.

There were no significant changes in CRP post-exercise in either condition or over time in the current study. These results are similar to previous studies using a similar exercise model (Miles et al. 2007, 2008) and indicate that even given the enhanced inflammation in the high $\mathrm{CHO}$ condition, that there was not enough muscle damage to induce a systemic inflammatory response. Studies with greater amounts of exercise stress including 300 maximal eccentric actions (Paulsen et al. 2005) and a 32-km mountain trail race (Miles et al. 2006) induced increases in CRP. It is possible that a similar exercise protocol utilizing a larger muscle group such as the legs could produce a more pronounced inflammatory response and would allow for more significant changes in the measures of inflammation. Given the results of the current 
study, it is worthwhile to investigate these dietary impacts on inflammation in the presence of a larger inflammatory stimulus.

While we were successful in differentiating inflamma-tion responses after eccentric exercise in the low compared to high $\mathrm{CHO}$ conditions, there are several limitations of the present study. One consideration for the increase in IL- $1 \beta$ at $24 \mathrm{~h}$ post-exercise is that subjects were not in the lab between 8 and $24 \mathrm{~h}$ post-exercise. It is possible that other factors (i.e. food intake, physical activity, etc.) could have influenced the increased IL-1 $\beta$. However, when consider-ing subjects' individual IL- $1 \beta$ responses it is likely that the CHO intake was the factor influencing the elevated IL- $1 \beta$. There were no obvious outliers causing this increase, and IL- $1 \beta$ was elevated in the majority of subjects at $24 \mathrm{~h}$ post-exercise in the high CHO condition. Additionally, the exercise used to induce inflammation is similar, but not identical, to weight-lifting, but the amount of muscle mass used was less than is typical for resistance exercise. Thus, we have demonstrated the potential for high and low $\mathrm{CHO}$ diets to influence inflammation, but further research with greater control during the post-exercise period and exercise stresses that are more applicable to the general population are needed.

In conclusion, there were two significant indications that high $\mathrm{CHO}$ intake resulted in a greater inflammatory response following eccentric exercise. IL- $1 \beta$ and perceived muscle soreness were greater in the high CHO compared to the low $\mathrm{CHO}$ condition. Additionally, there was a trend for IL- 6 to be greater in the high $\mathrm{CHO}$ condition. These results demonstrate that high $\mathrm{CHO}$ intake augmented inflamma-tion associated with skeletal muscle; however, lack of change in TNF- $\alpha$ and CRP indicate that the overall inflammation level remained somewhat low. It is beyond the scope of this study to make dietary $\mathrm{CHO}$ recommen-dations with respect to athletic performance and disease prevention. However, these results do support a need for additional investigations on the influence of macronutrient intake that are specifically targeted at both exercise per-formance and disease measures in specific populations.

\section{Acknowledgments}

This study was funded by the Department of Health and Human Development at Montana State University and an ADVANCE Leadership grant from the National Science Foundation.

\section{References}

* Aderka D, Sorkine P, Abu-Abid S, Lev D, Setton A, Cope AP, Wallach D, Klausner J (1998) Shedding kinetics of soluble tumor necrosis factor (TNF) receptors after systemic TNF leaking during isolated limb perfusion. Relevance to the pathophysiology of septic shock. J Clin Invest 101:650659

* Beutler BA, Milsark IW, Cerami A (1985) Cachectin/tumor necrosis factor: production, distribution, and metabolic fate in vivo. J Immunol 135:39723977

* Bruunsgaard H, Galbo H, Halkjaer-Kristensen J, Johansen TL, MacLean DA, Pedersen BK (1997) Exercise-induced increase in serum interleukin-6 in humans is related to muscle damage. J Physiol 499(Pt 3):833-841

* Dandona P, Chaudhuri A, Ghanim H, Mohanty P (2007) Proinflammatory effects of glucose and anti-inflammatory effect of insulin: relevance to cardiovascular disease. Am J Cardiol 99:15B-26B

* Davis JM, Murphy EA, Carmichael MD, Zielinski MR, Groschwitz CM, Brown AS, Gangemi JD, Ghaffar A, Mayer EP (2007) Curcumin effects on inflammation and performance recovery following eccentric exercise-induced muscle damage. Am J Physiol Regul Integr Comp Physiol 292:R2168-R2173

* Esposito K, Nappo F, Marfella R, Giugliano G, Giugliano F, Ciotola M, Quagliaro L, Ceriello A, Giugliano D (2002) Inflammatory cytokine concentrations are acutely increased by hyperglycemia in humans: role of oxidative stress. Circulation 106:2067-2072

* Faulkner JA, Brooks SV, Opiteck JA (1993) Injury to skeletal muscle fibers during contractions: conditions of occurrence and prevention. Phys Ther 73:911-921

${ }^{*}$ Flores EA, Bistrian BR, Pomposelli JJ, Dinarello CA, Blackburn GL, Istfan NW (1989) Infusion of tumor necrosis factor/cachectin promotes muscle catabolism in the rat. A synergistic effect with interleukin 1. J Clin Invest 83:1614-1622

* Foster-Powell K, Holt SH, Brand-Miller JC (2002) International table of glycemic index and glycemic load values: 2002. Am J Clin Nutr 76:5-56

* Gonzalez F, Minium J, Rote NS, Kirwan JP (2006) Altered tumor necrosis factor alpha release from mononuclear cells of obese reproductive-age women during hyperglycemia. Metabolism 55:271-276

* Grundy SM, Cleeman JI, Daniels SR et al (2005) Diagnosis and management of the metabolic syndrome: an American Heart Association/National Heart, Lung, and Blood Institute Scientific Statement. Circulation 112:2735-2752

* Hirose L, Nosaka K, Newton M, Laveder A, Kano M, Peake J, Suzuki K (2004) Changes in inflammatory mediators following eccentric exercise of the elbow flexors. Exerc Immunol Rev 10:75-90 
* Ivy JL, Ding Z, Hwang H, Cialdella-Kam LC, Morrison PJ (2008) Post exercise carbohydrate-protein supplementation: phosphorylation of muscle proteins involved in glycogen synthesis and protein translation. Amino Acids 35:89-97

* Loram LC, Fuller A, Fick LG, Cartmell T, Poole S, Mitchell D (2007) Cytokine profiles during carrageenan-induced inflammatory hyperalgesia in rat muscle and hind paw. J Pain 8:127-136

* Manninen AH (2006) Hyperinsulinaemia, hyperaminoacidaemia and post-exercise muscle anabolism: the search for the optimal recovery drink. Br $\mathrm{J}$ Sports Med 40:900-905

* Miles MP, Walker EE, Conant SB, Hogan SP, Kidd JR (2006) Carbohydrate influences plasma interleukin-6 but not C-reactive protein or creatine kinase following a 32-km mountain trail race. Int J Sport Nutr Exerc Metab 17:36-46

* Miles MP, Pearson SD, Andring JM, Kidd JR, Volpe SL (2007) Effect of carbohydrate intake during recovery from eccentric exercise on interleukin-6 and muscle-damage markers. Int J Sport Nutr Exerc Metab 17:507-520

* Miles MP, Andring JM, Pearson SD, Gordon LK, Kasper C, Depner CM, Kidd JR (2008) Diurnal variation, response to eccentric exercise, and association of inflammatory mediators with muscle damage variables. J Appl Physiol 104:451-458

* Moldawer LL, Svaninger G, Gelin J, Lundholm KG (1987) Interleukin 1 and tumor necrosis factor do not regulate protein balance in skeletal muscle. Am J Physiol 253:C766-C773

* Nawabi MD, Block KP, Chakrabarti MC, Buse MG (1990) Admin-istration of endotoxin, tumor necrosis factor, or interleukin 1 to rats activates skeletal muscle branched-chain alpha-keto acid dehydrogenase. J Clin Invest 85:256-263

* Negro M, Giardina S, Marzani B, Marzatico F (2008) Branched-chain amino acid supplementation does not enhance athletic perfor-mance but affects muscle recovery and the immune system. J Sports Med Phys Fitness 48:347-351

* Nehlsen-Cannarella SL, Fagoaga OR, Nieman DC, Henson DA, Butterworth DE, Schmitt RL, Bailey EM, Warren BJ, Utter A, Davis JM (1997) Carbohydrate and the cytokine response to $2.5 \mathrm{~h}$ of running. J Appl Physiol 82:1662-1667

* Nieman DC, Davis JM, Brown VA, Henson DA, Dumke CL, Utter AC, Vinci DM, Downs MF, Smith JC, Carson J, Brown A, McAnulty SR, McAnulty LS (2004) Influence of carbohydrate ingestion on immune changes after $2 \mathrm{~h}$ of intensive resistance training. J Appl Physiol 96:1292-1298

* Nosaka K, Clarkson PM, McGuiggin ME, Byrne JM (1991) Time course of muscle adaptation after high force eccentric exercise. Eur J Appl Physiol Occup Physiol 63:70-76

* Ostrowski K, Rohde T, Asp S, Schjerling P, Pedersen BK (1999) Pro- and anti-inflammatory cytokine balance in strenuous exercise in humans. J Physiol 515(Pt 1):287-291

* Paulsen G, Benestad HB, Strom-Gundersen I, Morkrid L, Lappegard KT, Raastad T (2005) Delayed leukocytosis and cytokine response to high-force eccentric exercise. Med Sci Sports Exerc 37:1877-1883

* Pearson TA, Mensah GA, Alexander RW et al (2003) Markers of inflammation and cardiovascular disease: application to clinical and public health practice: A statement for healthcare profes-sionals from the Centers for Disease Control and Prevention and the American Heart Association. Circulation 107:499-511

* Pedersen BK, Ostrowski K, Rohde T, Bruunsgaard H (1998) The cytokine response to strenuous exercise. Can J Physiol Pharmacol 76:505-511

* Petersen AM, Pedersen BK (2005) The anti-inflammatory effect of exercise. J Appl Physiol 98:1154-1162

* Plomgaard P, Bouzakri K, Krogh-Madsen R et al (2005) Tumor necrosis factor-alpha induces skeletal muscle insulin resistance in healthy human subjects via inhibition of Akt substrate 160 phosphorylation. Diabetes 54:2939-2945

* Proske U, Morgan DL (2001) Muscle damage from eccentric exercise: mechanism, mechanical signs, adaptation and clinical applications. J Physiol $537: 333-345$

* Silva LA, Silveira PC, Pinho CA, Tuon T, Dal Pizzol F, Pinho RA (2008) N-acetylcysteine supplementation and oxidative damage and inflammatory response after eccentric exercise. Int J Sport Nutr Exerc Metab 18:379-388

* Smith LL, Miles MP (2000) Exercise-induced muscle injury and inflammation. In: Garrett WE, Kirkendall DT (eds) Exercise and sport science. Lippincott Williams \& Wilkins, Philadelphia, pp 401-411

* Smith LL, Anwar A, Fragen M, Rananto C, Johnson R, Holbert D (2000) Cytokines and cell adhesion molecules associated with high-intensity eccentric exercise. Eur J Appl Physiol 82:61-67 Tidball JG (2005) Inflammatory processes in muscle injury and repair. Am J Physiol Regul Integr Comp Physiol 288:R345-R353

* Tilg H, Moschen AR (2008) Inflammatory mechanisms in the regulation of insulin resistance. Mol Med 14:222-231 